\title{
THE MATHEMATICAL MODEL OF FORECASTING THE PRICE LEVEL IN THE REGIONAL MARKET OF RESIDENTIAL REAL ESTATE ${ }^{1}$
}

\author{
Ekaterina V. Voronina \\ Crimean Federal University named after V.I. Vernadsky, Simferopol, Russian Federation; \\ Don State Technical University, Rostov-on-Don, Russian Federation \\ Olga B. Yarosh \\ Crimean Federal University named after V.I. Vernadsky, Simferopol, Russian Federation \\ Natalya V. Bereza \\ Don State Technical University, Shakhty, Russian Federation \\ Marina V. Rossinskaya \\ Sochi State University, Sochi, Russian Federation
}

\begin{abstract}
The purpose of this article is to develop a mathematical model for estimating the value of a real estate object, taking into account the trends in the residential real estate market using indicators of the object's state and indicators of the real estate market. The real estate market is a complex mechanism that includes subjects, objects, processes and infrastructure. The real estate market has its own characteristics that distinguish it from the market of goods and services related to the duality of real estate, its special characteristics. Despite the high conservatism, there are certain innovative trends in the development of the residential real estate market (innovations in construction, architecture, services and marketing, logistics, customer focus).

The article considers the residential real estate market as a complex socio-technical system, to predict the development of which it is advisable to use a combination of classical forecasting methods and soft computing or intelligent data processing methods. A forecast of the development of the residential real estate services market was made using foresight technologies (industry roadmap). The analysis was carried out and the main factors $\oplus$ acting on the market were identified, and their influence on the development of market trends was determined. $\sum$ A mathematical model for predicting the value of residential real estate based on the theory of fuzzy sets has been developed.

Key words: services, services sector, real estate market, residential real estate, forecasting, roadmap, mathematical model, the state of a real estate object, the state of real estate market.

Citation. Voronina E.V., Yarosh O.B., Bereza N.V., Rossinskaya M.V. The Mathematical Model of Forecasting the Price Level in the Regional Market of Residential Real Estate. Vestnik Volgogradskogo gosudarstvennogo universiteta. Seriya 3, Ekonomika. Ekologiya [Science Journal of Volgograd State University. Global Economic System], 2019, vol. 21, no. 1, pp. 40-55. (in Russian). DOI: https://doi.org/10.15688/jvolsu3.2019.1.4

\section{МАТЕМАТИЧЕСКАЯ МОДЕЛЬ ПРОГНОЗИРОВАНИЯ УРОВНЯ ЦЕН НА РЕГИОНАЛЬНОМ РЫНКЕ ЖИЛОЙ НЕДВИЖИМОСТИ ${ }^{1}$}

\section{Екатерина Владимировна Воронина}

Крымский федеральный университет им. В.И. Вернадского, г. Симферополь, Российская Федерация; Донской государственный технический университет, г. Ростов-на-Дону, Российская Федерация 
Математическая модель прогнозирования уровня цен на региональном рынке жилой недвижимости

\section{Ольга Борисовна Ярош}

Крымский федеральный университет им. В.И. Вернадского, г. Симферополь, Российская Федерация

\section{Наталья Викторовна Береза}

Донской государственный технический университет, г. Шахты, Российская Федерация

\section{Марина Васильевна Россинская}

Сочинский государственный университет, г. Сочи, Российская Федерация

Аннотация. Цель данной статьи состоит в разработке математической модели оценки стоимости объекта с учетом тенденций на рынке жилой недвижимости с помощью показателей состояния объекта недвижимости и показателей состояния рынка недвижимости. Рынок недвижимости - это сложный механизм, который включает в себя субъекты, объекты, процессы и инфраструктуру. Рынок недвижимости имеет свои особенности, которые отличают его от рынка товаров и услуг, связанные с двойственностью недвижимости, ее особыми характеристиками. Несмотря на высокую консервативность, существуют определенные инновационные тенденции в развитии рынка жилой недвижимости (инновации в строительстве, архитектуре, сфере услуг и маркетинга, логистике, клиентоориентированности).

В статье рассматривается рынок жилой недвижимости как сложная социально-техническая система, для прогнозирования развития которой целесообразно применять сочетание классических методов прогнозирования и мягких вычислений или интеллектуальных методов обработки данных. Составлен прогноз развития рынка услуг жилой недвижимости с помощью форсайт-технологий (отраслевая дорожная карта). Проведен анализ и выявлены основные факторы, действующие на рынке, и определено их влияние на развитие рыночных тенденций. Разработана математическая модель прогнозирования стоимости жилой недвижимости на основе теории нечетких множеств.

Ключевые слова: услуги, сфера услуг, рынок недвижимости, жилая недвижимость, прогнозирование, дорожная карта, математическая модель, состояние объекта недвижимости, состояние рынка недвижимости.

Цитирование. Воронина Е. В., Ярош О. Б., Береза Н. В., Россинская М. В. Математическая модель прогнозирования уровня цен на региональном рынке жилой недвижимости // Вестник Волгоградского государственного университета. Серия 3, Экономика. Экология. - 2019. - Т. 21, № 1. - С. 40-55. - DOI: https://doi.org/10.15688/jvolsu3.2019.1.4

\section{Постановка проблемы}

Прогнозирование представляет собой анализ будущего состояния объекта, предмета, товара или услуги. Оно представляет собой сложный процесс, для производства которого необходимо применять в сочетании различные методы прогнозирования. На сегодняшний день существует огромное множество методов прогнозирования, из которых только 15-20 используются на практике (см. рис. 1) [1;2].

Укрупненно методы прогнозирования разделяют на интуитивные и формализованные. Их отличие состоит в том, что формализованные методы позволяют выразить результаты количественно (в основном их объясняют математические модели), а интуитивные методы носят качественный характер, и, как правило, получены из опыта (суждения и оценки экспертов) [13].
На практике при проведении исследований и составлении прогнозов применяется сочетание нескольких методов прогнозирования. На первом этапе исследования обычно используются интуитивные методы (анкетный опрос, интервьюирование, коллективные экспертные оценки и др.), после сбора первичной информации происходит построение математической модели. Выбор методов математического моделирования определяется особенностями моделируемой области. Для социально-экономических систем характерны следующие особенности: многоаспектность происходящих в них процессов (экономических, социальных и т. п.) и их взаимосвязанность; в силу этого невозможно вычленение и детальное исследование отдельных явлений - все происходящие в них явления должны рассматриваться в совокупности; отсутствие достаточной количественной информации о динамике процессов вынуждает переходить к каче- 
ственному анализу таких процессов; изменчивость характера процессов во времени и т. д. Поэтому в настоящее время при построении математических моделей социальных и экономических процессов все большую популярность приобретают интеллектуальные модели и методы обработки данных.

Для принятия решений в условиях неопределенности используются разные методы принятия решений: экспертный опрос; вероятностные модели; нечеткие вычисления; интервальная математика; теория игр; метод анализа иерархий [6;14].

Необходимо провести анализ методов по таким критериям, как: возможность производить неполные парные сравнения, учитывать нечеткость, неточность в параметрах, характеризующих объект исследования, использовать лингвистические значения параметров и одновременно производить некоторую количественную оценку альтернатив, включать в исследования количественные оценки объектов (табл. 1).

Наиболее подходящей для создания модели является теория нечетких множеств, так как она позволяет оперировать с лингвисти- ческими значениями показателей и переводить их в количественные (с учетом специфики предприятия и видов деятельности), легко корректировать значения показателей на стадии перехода к нечеткости, имитировать процесс человеческого мышления и поведения, а также с успехом принимать решения в условиях недостатка информации.

Состояние рынка подвержено влиянию самых разнообразных факторов, среди которых можно выделить: цены на нефть, занятость населения, инфляцию, расходы госбюджета, доходы населения, колебания деловой активности, класс жилья, количество комнат, ставки по кредитам, объемы первичного и вторичного рынков.

Следует отметить следующие закономерности функционирования рынка жилой недвижимости: эластичность спроса на жилье зависит от типа комнатности (спрос на однои двухкомнатные квартиры менее эластичен по цене); цены на однокомнатные квартиры в пересчете на квадратный метр будут соответственно дороже, чем многокомнатные; прямой зависимости цен на недвижимость от курса цен на нефть нет, поэтому частичное сни-

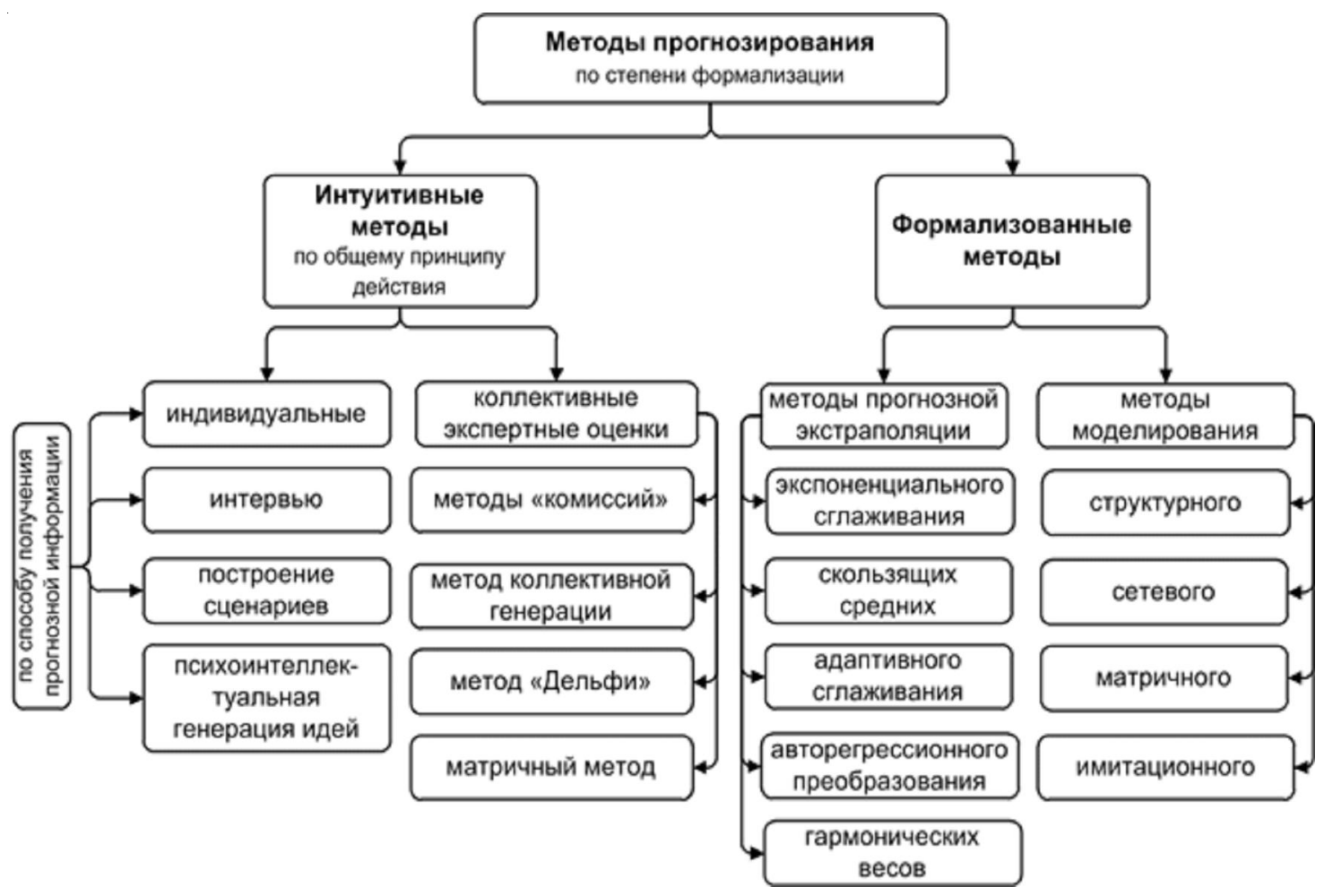

Рис. 1. Наиболее популярные методы прогнозирования

Примечание. Разработано авторами. 
Математическая модель прогнозирования уровня цен на региональном рынке жилой недвижимости

жение цен на нефть положительно влияет на снижение цен на недвижимость; рост доходов приводит к непосредственному росту цен на жилье, исключение составляет лишь инфляция и падение деловой активности, при инфляции цены на недвижимость увеличиваются, а при падении деловой активности - уменьшаются. Важным фактором при определении цены на недвижимость является насыщенность рынка: чем больше предложений жилья, тем оно дешевле; первичное жилье, на которое больший спрос, вытесняет два класса жилья - вторичное и элитное.

\section{Прогнозирование развития рынка услуг недвижимости с помощью дорожного картирования}

Дорожная карта является пошаговым графическим представлением прогнозных значений определенного объекта, товара, услуги.

Дорожное картирование в экономической литературе встречается как синоним таких понятий, как бизнес-планирование и форсайт. Если бизнес-план - это определенный план или программа четких действий компании, то форсайт - это методика долгосрочного прогнозирования научно-технологического и социального развития, основанная на опросе экспер- тов. Дорожная карта, ее разработка и представление, является частным методом представления результатов форсайт-технологий.

В России пока еще недостаточно распространен такой инструмент планирования, как дорожное картирование, поэтому еще не сформированы унифицированные методические подходы и алгоритмы формирования и построения дорожных карт. Графическое представление, структура и форма дорожной карты четко не заданы.

В зависимости от объекта дорожного картирования выделяют следующие виды дорожных карт (см. рис. 2).

В данной работе будет рассматриваться отраслевая дорожная карта, описывающая прогнозирование развития рынка услуг в сфере жилой недвижимости.

Для составления дорожной карты были рассмотрены тенденции развития рынка услуг в сфере недвижимости; вызовы (проблемы и факторы, влияющие на рынок жилой недвижимости); требования к компаниям, которые предоставляют услуги в сфере недвижимости; субъекты, которые непосредственно оказывают влияние на развитие рынка услуг в сфере недвижимости; инновации, которые выступают в качестве катализаторов развития рынка услуг недвижимости (см. рис. 3).

Сравнение границ применения методов принятий решений

Таблица 1 в условиях неопрделенности

\begin{tabular}{|c|c|c|c|c|c|c|}
\hline Критерии & $\begin{array}{l}\text { Метод при- } \\
\text { нятия реше- } \\
\text { ний на осно- } \\
\text { ве нечеткой } \\
\text { логики } \\
\end{array}$ & $\begin{array}{l}\text { Метод ана- } \\
\text { лиза иерар- } \\
\text { хий }\end{array}$ & $\begin{array}{c}\text { Качествен- } \\
\text { ные методы } \\
\text { принятий } \\
\text { решений }\end{array}$ & $\begin{array}{l}\text { Вероятност- } \\
\text { ные модели }\end{array}$ & $\begin{array}{l}\text { Интерваль- } \\
\text { ная матема- } \\
\text { тика }\end{array}$ & Теория игр \\
\hline $\begin{array}{l}\text { Возможность производить } \\
\text { неполные парные сравнения }\end{array}$ & + & - & - & - & - & - \\
\hline $\begin{array}{l}\text { Возможность учитывать не- } \\
\text { четкость, неточность в па- } \\
\text { раметрах, характеризующих } \\
\text { объект исследования }\end{array}$ & + & - & + & - & + & - \\
\hline $\begin{array}{l}\text { Возможность использовать } \\
\text { лингвистические значения } \\
\text { параметров }\end{array}$ & + & - & + & - & - & - \\
\hline $\begin{array}{l}\text { Получение некоторой коли- } \\
\text { чественной оценки альтер- } \\
\text { натив }\end{array}$ & + & + & - & + & + & + \\
\hline $\begin{array}{l}\text { Возможность включать в } \\
\text { исследования количествен- } \\
\text { ные оценки объектов } \\
\end{array}$ & + & + & + & + & + & + \\
\hline
\end{tabular}

Примечание. Разработано авторами по: [6]. 


\section{РЕГИОНАЛЬНАЯ ЭКОНОМИКА}

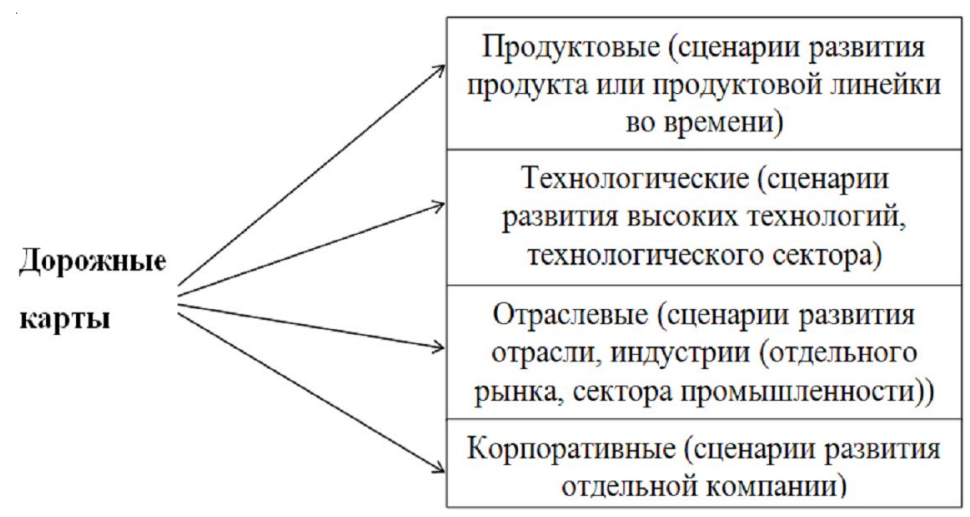

Рис. 2. Виды дорожных карт

Примечание. Разработано авторами.

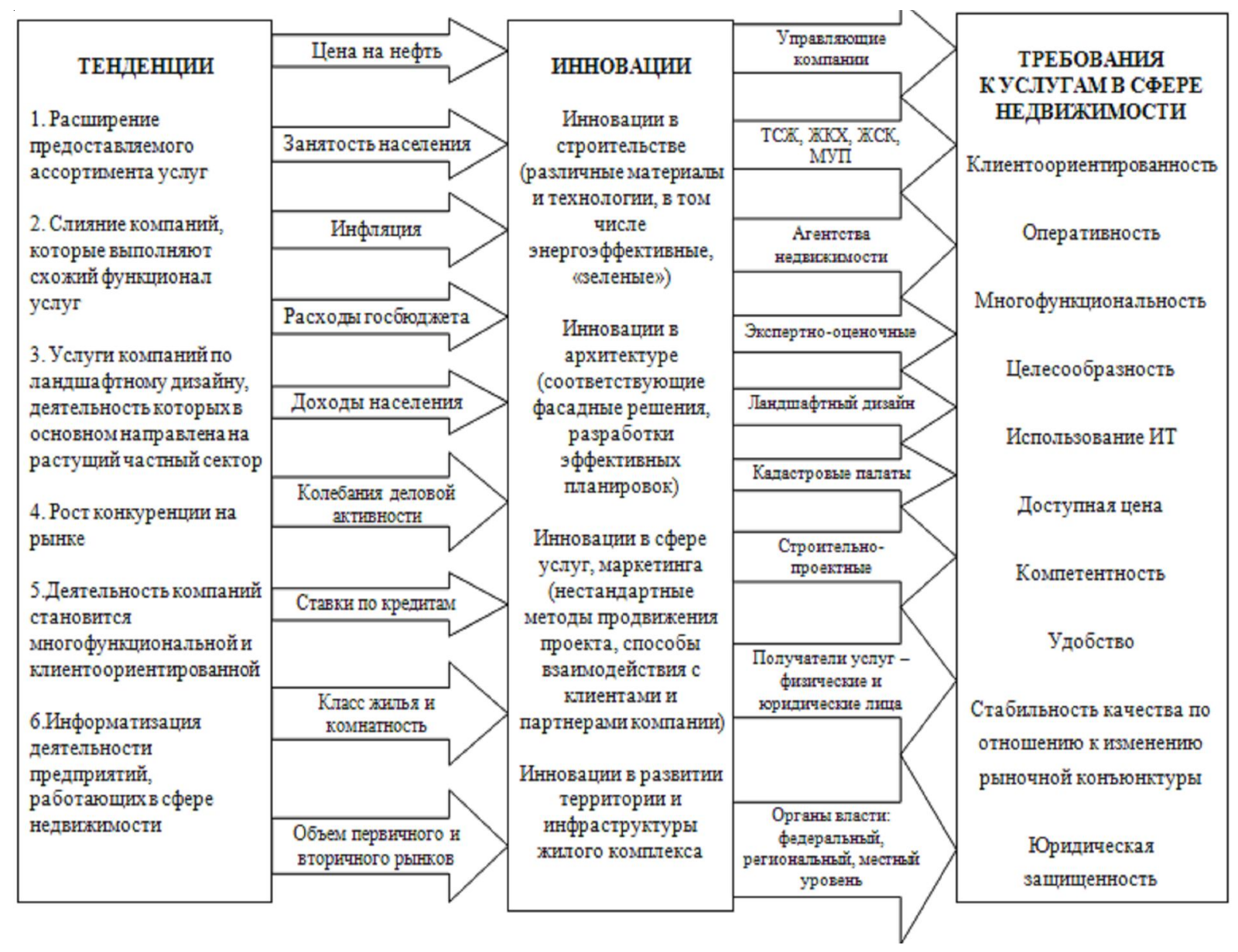

Рис. 3. Дорожная карта развития рынка услуг недвижимости

Примечание. Разработано авторами.

Для того чтобы реализовать требования, предъявляемые к услугам, необходимо разработать алгоритм процесса регулирования рынка недвижимости, представленный на рисунке 4.

С помощью дорожного картирования был проведен анализ микро- и макросреды рынка недвижимости, желаемого (целевого) состояния рынка, выявлены факторы, влияющие на состояние рынка услуг (ускоряющие и тормозящие). Предложен алгоритм управления развитием рынка жилой недвижимости. Для оценки состояния рынка жилой недвижимости необходимо создание интегрированного количественного показателя, позволяющего учесть особенности объекта оценки. 
Математическая модель прогнозирования уровня цен на региональном рынке жилой недвижимости

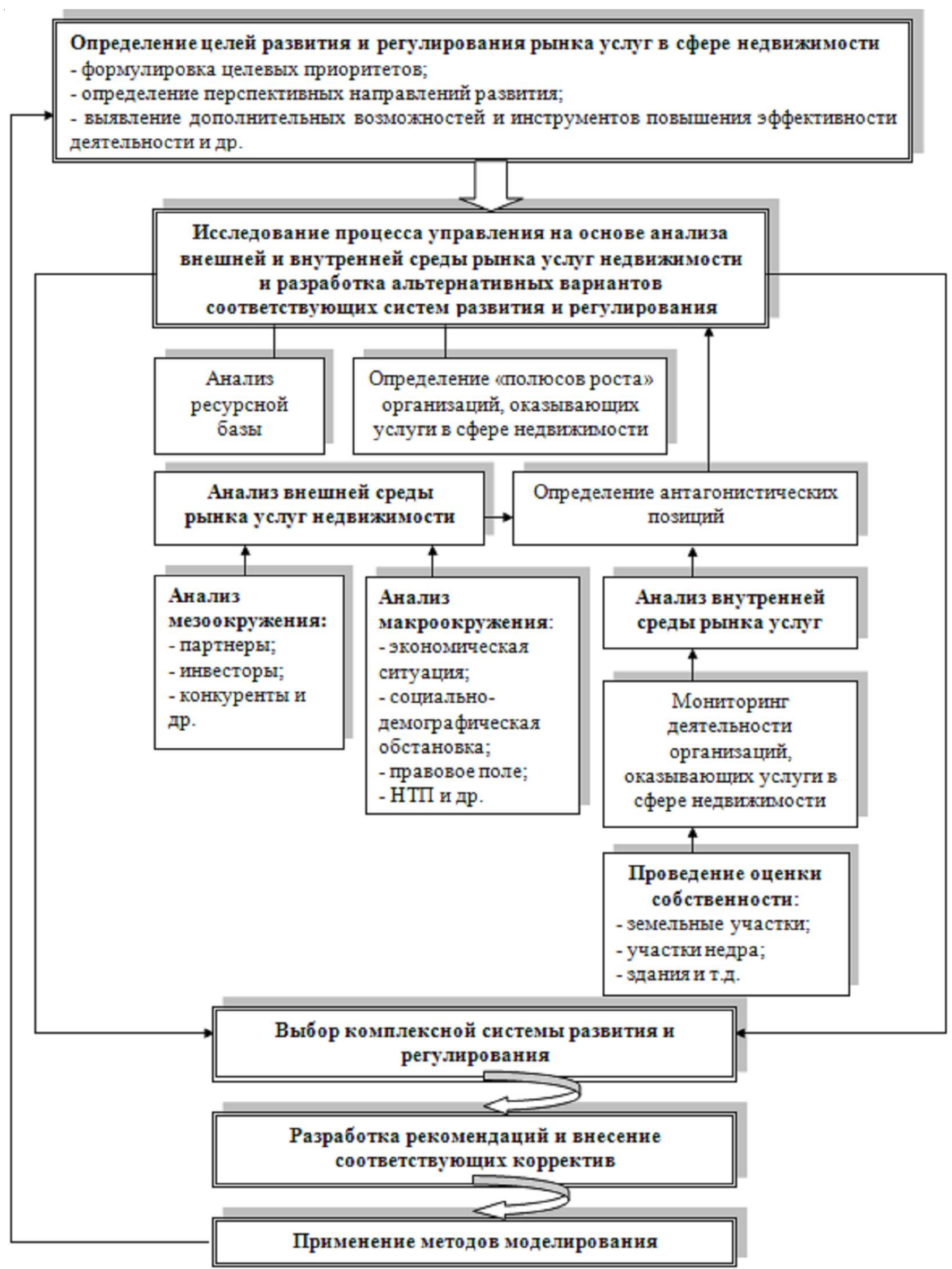

Рис. 4. Алгоритм процесса регулирования рынка недвижимости

Примечание. Разработано авторами по: [4; 5].

\section{Разработка математической модели оценки стоимости объекта с учетом тенденций на рынке жилой недвижимости}

Вопросы оценки показателей рынка жилой недвижимости приобретают особую актуальность. Показатели, характеризующие рынок жилой недвижимости, носят комплексный характер, включают в себя несколько составляющих и достаточно сложно формализуются.

Комплексный показатель, характеризующий уровень цен на рынке жилой недвижимости, может, например, включать в себя следующие составляющие: местоположение 
объекта; отделка; класс и площадь жилья; доходы населения; уровень инфляции; ставки по кредитам [3; 9].

Таким образом, при оценке рынка жилой недвижимости необходимо создание интегрированного показателя, позволяющего учесть особенности объекта оценки. Также очевидно, что структура показателя стоимости на рынке жилой недвижимости нуждается в динамической подстройке в связи с изменением значимости отдельных составляющих в зависимости от конъюнктуры рынка. При этом некоторые показатели, такие как «качество отделки» и «местоположение объекта», не имеют количественных измерителей, что требует применения лингвистических значений, следовательно, наиболее подходящим математическим инструментарием является теория нечетких множеств $[10 ; 12]$.

Комплексный показатель, характеризующий уровень цен на рынке жилой недвижимости, включает в себя 2 группы переменных: связанных с состоянием самого объекта (местоположение объекта, качество отделки, класс и площадь жилья) и состоянием рынка недвижимости (доходы населения, уровень инфляции и ставки по кредитам). Данная нечеткая система оценки стоимости объекта жилой недвижимости будет включать следующие переменные (формулы 1-3):

$$
\lambda_{1}=f_{1}\left(x_{1}, x_{2}, x_{3}, x_{4}\right)
$$

где $\lambda_{1}$ - состояние объекта недвижимости; $x_{1}-$ местоположение объекта; $x_{2}$ - отделка; $x_{3}$ - класс жилья; $x_{4}-$ площадь жилья;

$$
\lambda_{2}=f_{2}\left(x_{5}, x_{6}, x_{7}\right),
$$

где $\lambda_{2}$ - состояние рынка недвижимости; $x_{5}-$ доходы населения; $x_{6}$ - уровень инфляции; $x_{7}-$ ставки по кредитам;

$$
\varphi_{1}=f_{3}\left(\lambda_{1}, \lambda_{2}\right)
$$

где $\varphi_{1}-$ стоимость 1 кв. м объекта жилой недвижимости; $f_{1}, f_{2}, f_{3}$ - функции нечеткого вывода.

Итоговая система нечеткого вывода показателя стоимости в качестве входов получает значения из промежуточных баз знаний $\lambda_{1}, \lambda_{2}[15]$.
При построении функций принадлежности каждого нечеткого значения приведенных критериев необходимо задать узловые точки и по ним построить классификатор. При построении оценочных шкал необходимо учитывать особенности показателей и соответственно выбирать тип и размерность шкалы.

Показатель «стоимость объекта жилой недвижимости» является комплексным, поэтому рассмотрим отдельно шкалы для всех его составляющих.

\section{Нечеткие оценки критериев состояния объекта недвижимости}

Местоположение объекта недвижимости - это комплексная характеристика, которая может включать в себя и удаленность от центра, доступность социальной инфраструктуры (поликлиника, школа, садик, почта, магазины, отделения банков и т. п.), транспортную доступность (расстояние до остановки, количество видов транспорта, маршрутов) и обустроенность придомовой территории (наличие парковочных мест, детских площадок, мест отдыха и т. п.) [11].

Для более обобщенной характеристики местоположения объекта недвижимости могут быть применены только качественные значения «непрестижное», «не очень престижное», «достаточно престижное» и «очень престижное» (см. рис. 5).

Для нечеткой переменной «местоположение объекта» определены следующие лингвистические термы: $k_{1}-$ непрестижное; $k_{2}-$ не очень престижное; $k_{3}$ - достаточно престижное; $k_{4}$ - очень престижное.

Была определена шкала от 0 до 200, где 100 - соответствует достаточно престижному уровню и функция принадлежности терма «достаточно престижное» в этой точке равна 1. Далее были определены узловые точки, а по этим узловым точкам построены кусочно-линейные и трапециевидные функции принадлежности для всех термов. При этом соблюдены требования стандартных классификаторов - сумма всех функций принадлежности для любого $x$ равна единице.

Для этих термов определены следующие функции принадлежности (формула 4): 
Математическая модель прогнозирования уровня цен на региональном рынке жилой недвижимости

$$
\begin{gathered}
\mu_{k_{1}}(x)=\left\{\begin{array}{c}
1,0 \leq x<50 \\
\frac{80-x}{30}, 50<x<80 \\
0, x \geq 80
\end{array}\right. \\
\mu_{k 2}(x)=\left\{\begin{array}{c}
0, x \leq 50 \\
\frac{x-50}{30}, 50<x<80 \\
1,80 \leq x \leq 100 \\
\frac{120-x}{20}, 100<x<120 \\
0, x \geq 120
\end{array}\right. \\
\mu_{k 3}(x)=\left\{\begin{array}{c}
0, x \leq 100 \\
\frac{x-100}{20}, 100<x<120 \\
1,120 \leq x \leq 140 \\
\frac{160-x}{20}, 140<x<160 \\
0, x \geq 160
\end{array}\right. \\
\mu_{k 4}(x)=\left\{\begin{array}{c}
\frac{x-140}{1,160}, 140<x<200 \\
0, x \leq 140
\end{array}\right.
\end{gathered}
$$

Примечание. Разработано авторами по: [7].

Показатель качества отделки - показатель, характеризующий качество обработки и покрытий, а также декоративность и функциональность элементов отделки, внешних поверхностей.

Существуют различные типы отделки квартир и домов.

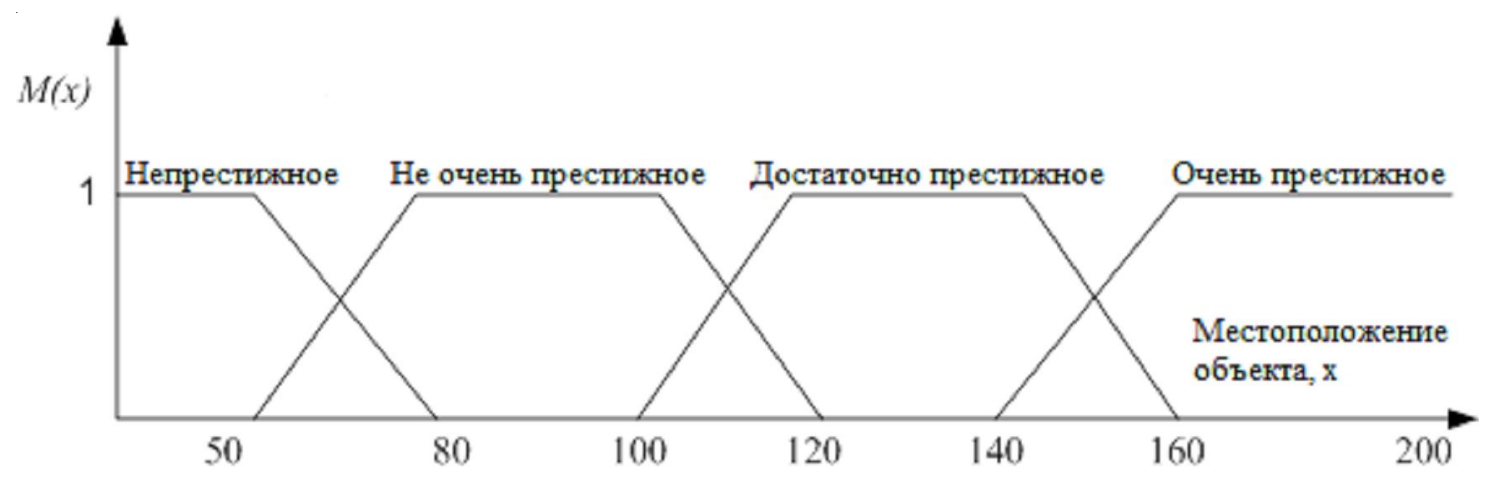

Рис. 5. Функции принадлежности и значения лингвистической переменной «местоположение объекта» Примечание. Разработано авторами. 


\section{РЕГИОНАЛЬНАЯ ЭКОНОМИКА}

$$
\begin{aligned}
& \mu_{k 2}(x)=\left\{\begin{array}{c}
0, x \leq 40 \\
\frac{x-40}{20}, 40<x<60 \\
1,60 \leq x \leq 80 \\
\frac{100-x}{20}, 80<x<100 \\
0, x \geq 100
\end{array}\right. \\
& \mu_{k 3}(x)=\left\{\begin{array}{c}
\frac{x-80}{20}, 80<x<100 \\
1,100 \leq x \leq 120 \\
\frac{140-x}{20}, 120<x<140 \\
0, x \geq 140
\end{array}\right. \\
& \mu_{k 4}(x)=\left\{\begin{array}{c}
\frac{x-140 \leq x \leq 200}{20}, 120<x<140 \\
0, x \leq 120
\end{array}\right.
\end{aligned}
$$

Примечание. Разработано авторами по: [7].

Несмотря на то что единой утвержденной классификации жилой недвижимости сегодня не существует, на практике отечественный рынок имеет все-таки довольно четкое деление на сегменты. С каждым годом классификация рынка становится все более осязаемой, у каждого сегмента появляются определенные признаки. Так, говоря о недвижимости в каком-либо регионе, можно выделить три класса жилья: эконом, комфорт и элит.

В состав нечеткой переменной «класс жилья» включены три компонента, и для

каждого определены лингвистические термы: $k_{1}$ - эконом; $k_{2}$ - стандарт; $k_{3}$ - элит.

Для этих термов определены следующие функции принадлежности (формула 6):

$$
\begin{gathered}
\mu_{k_{1}}(x)=\left\{\begin{array}{c}
1,0 \leq x \leq 60 \\
\frac{90-x}{30}, 60<x<90 \\
0, x \geq 90
\end{array}\right. \\
\mu_{k 2}(x)=\left\{\begin{array}{c}
0, x \leq 60 \\
\frac{x-60}{30}, 60<x<90 \\
1,90 \leq x \leq 110 \\
\frac{140-x}{30}, 110<x<140 \\
0, x \geq 140
\end{array}\right. \\
\mu_{k 3}(x)=\left\{\begin{array}{c}
1,140 \leq x \leq 200 \\
\frac{x-110}{30}, 110<x<140 \\
0, x \leq 110
\end{array}\right.
\end{gathered}
$$

Примечание. Разработано авторами по: [7].

Оценочная шкала также была выбрана от 0 до 200, где 100 - соответствует среднему сроку стандартного варианта и функция принадлежности терма «стандарт» в этой точке равна 1 (см. рис. 7).

Для компонента «площадь недвижимости» приняты лингвистические термы: $k_{1}-$ малогабаритное жилье; $k_{2}$ - среднегабаритное жилье; $k_{3}-$ крупногабаритное жилье. Для этих термов определены следующие функции принадлежности (формула 7):

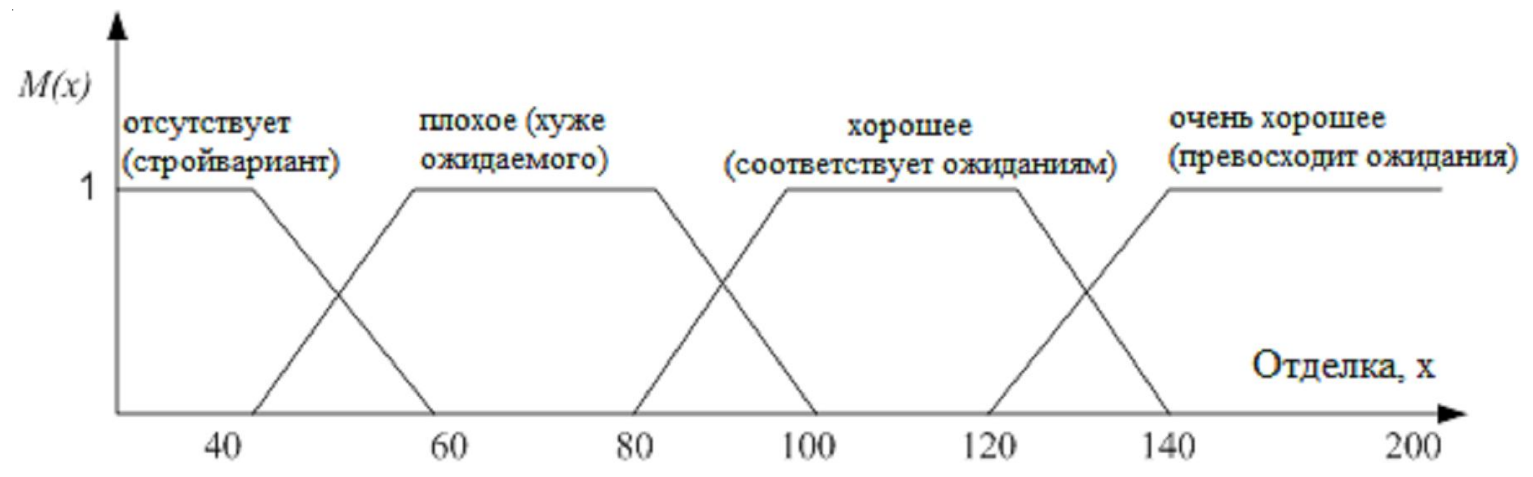

Рис. 6. Функции принадлежности и значения лингвистической переменной «качество отделки» Примечание. Разработано авторами. 
Математическая модель прогнозирования уровня цен на региональном рынке жилой недвижимости

$$
\begin{gathered}
\mu_{k_{1}}(x)=\left\{\begin{array}{c}
1,0 \leq x \leq 60 \\
\frac{90-x}{30}, 60<x<90 \\
0, x \geq 90
\end{array}\right. \\
\mu_{k 2}(x)=\left\{\begin{array}{c}
0, x \leq 60 \\
\frac{x-60}{30}, 60<x<90 \\
1,90 \leq x \leq 110 \\
\frac{140-x}{30}, 110<x<140 \\
0, x \geq 140
\end{array}\right.
\end{gathered}
$$$$
\mu_{k 3}(x)=\left\{\begin{array}{c}
1,140 \leq x \leq 200 \\
\frac{x-110}{30}, 110<x<140 \\
0, x \leq 110
\end{array}\right.
$$

Примечание. Разработано авторами по: [7].

Оценочная шкала также была выбрана от 0 до 200, где 100 - соответствует стандартному варианту площади недвижимости и функция принадлежности терма «среднегабаритное жилье» в этой точке равна 1 (рис. 8). База правил нечеткого вывода представлена в таблице 2.

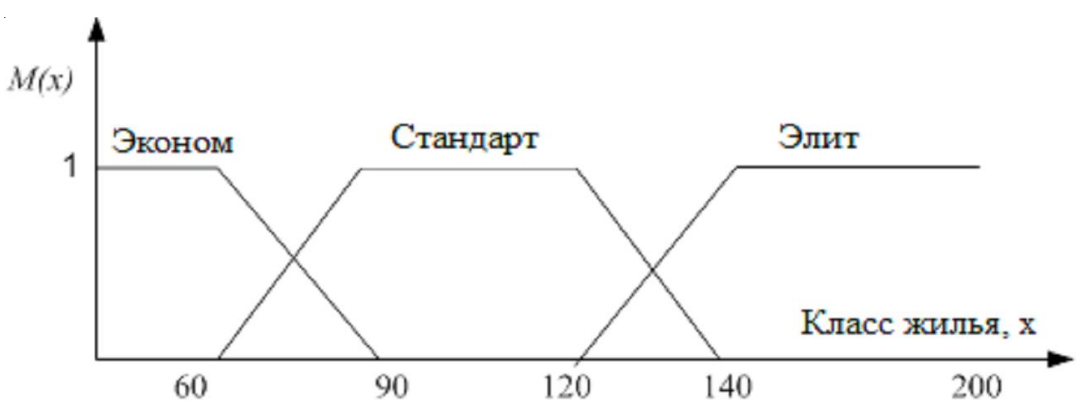

Рис. 7. Функции принадлежности и значения лингвистической переменной «класс жилья» Примечание. Разработано авторами.

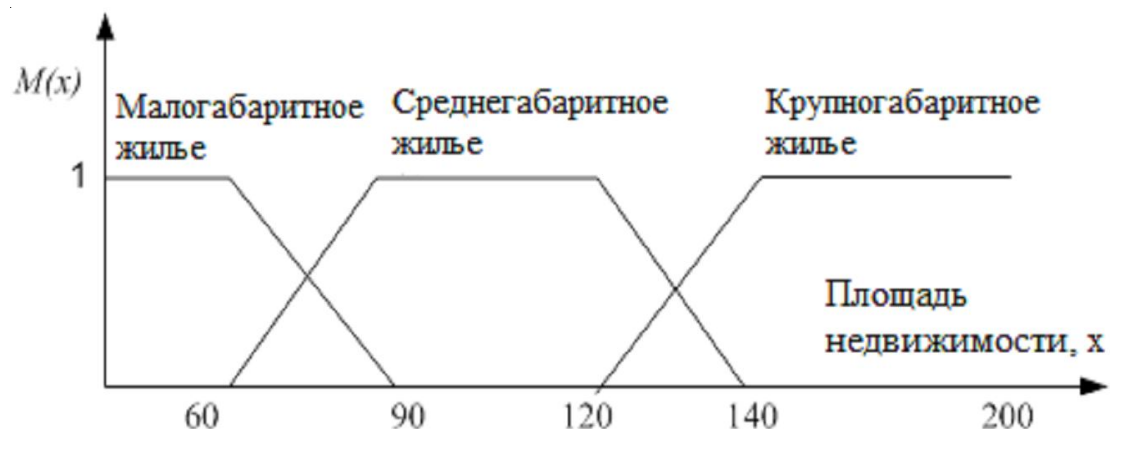

Рис. 8. Функции принадлежности и значения лингвистической переменной «площадь недвижимости»

Примечание. Разработано авторами.

Таблица 2

База правил вывода нечеткого значения «площадь недвижимости»

\begin{tabular}{|l|l|c|}
\hline Комнатность & \multicolumn{1}{|c|}{ Метраж } & Габаритность \\
\hline 1-комнатная & До 25 кв. м & $k_{1}$ \\
\cline { 2 - 3 } & 26-40 кв. м & $k_{2}$ \\
\cline { 2 - 3 } & 41 кв. м и более & $k_{3}$ \\
\hline 2-комнатная & До 40 кв. м & $k_{1}$ \\
\cline { 2 - 3 } & $40-50$ кв. м & $k_{2}$ \\
\cline { 2 - 3 } & 51 кв. м и более & $k_{3}$ \\
\hline \multirow{5}{*}{$\begin{array}{l}\text { 3-комнатная } \\
\text { и более }\end{array}$} & До 50 кв. м & $k_{1}$ \\
\cline { 2 - 3 } & До 60 кв. м & $k_{2}$ \\
\cline { 2 - 3 } & Свыше 61 кв. м & $k_{3}$ \\
\hline
\end{tabular}

Примечание. Разработано авторами. 


\section{РЕГИОНАЛЬНАЯ ЭКОНОМИКА}

\section{Нечеткие оценки критериев состояния рынка недвижимости}

Поскольку недвижимость является достаточно дорогостоящим товаром, на состояние рынка недвижимости, точнее на величину спроса, сильное влияние оказывает уровень дохода населения. Уровень доходов населения в различных субъектах РФ и в отдельных населенных пунктах одного субъекта может существенно отличаться. Для построения математической модели будем оценивать уровень дохода в населенном пункте по сравнению со средним по региону [8].

Для лингвистической переменной «доходы населения» определим следующие значения термов: «ниже среднего по области», «соответствует среднему», «выше среднего по области» (рис. 9).

Для этих термов определены следующие функции принадлежности (формула 8):

$$
\begin{aligned}
& \mu_{k_{1}}(x)=\left\{\begin{array}{c}
1,0,8 R \geq x \\
\frac{0,9 R-x}{0,1 R}, 0,8 R<x<0.9 R \\
0, x \geq 0,9 R
\end{array}\right. \\
& \mu_{k 2}(x)=\left\{\begin{array}{c}
0, x \leq 0,8 R \\
\frac{x-0,8 R}{0,1 R}, 0,8 R<x<0,9 R \\
1,0,9 R \leq x \leq 1,1 R \\
\frac{1,2 R-x}{0,1 R}, 1,1 R<x<1,2 R \\
0, x \geq 1,2 R
\end{array}\right.
\end{aligned}
$$

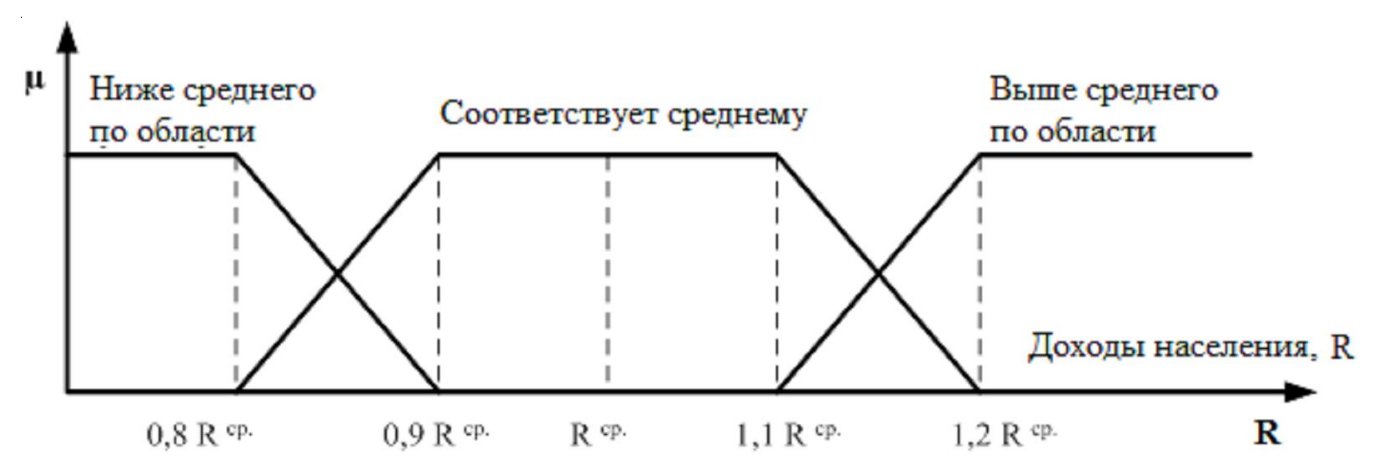

Рис. 9. Нечеткая шкала для показателя «доходы населения»

Примечание. Разработано авторами.

$$
\mu_{k 3}(x)=\left\{\begin{array}{c}
1, x \geq 1,2 R \\
\frac{x-1,1 R}{0,1 R}, 1,1 R<x<1,2 R \\
0, x \leq 1,1 R
\end{array}\right.
$$

где $R$ - средний уровень доходов по регионам, тыс. руб. на душу населения.

Примечание. Разработано авторами по: [7].

Оценочная шкала для компонента «уровень инфляции» также построена на основе среднего уровня инфляции по региону. Далее были определены узловые точки, а по этим узловым точкам построены кусочно-линейные и трапециевидные функции принадлежности для всех термов (см. рис. 10).

Для компонента «уровень инфляции» определены значения переменной: $k_{1}-$ ниже среднего по области; $k_{2}$ - соответствует среднему; $k_{3}$ - выше среднего по области.

Для этих термов определены следующие функции принадлежности (формула 9):

$$
\begin{aligned}
& \mu_{k_{1}}(x)=\left\{\begin{array}{c}
1, x \leq 0,8 I \\
\frac{0,9 I-x}{0,1 I}, 0,8 I<x<0.9 I \\
0, x \geq 0,9 I
\end{array}\right. \\
& \mu_{k 2}(x)=\left\{\begin{array}{c}
0, x \leq 0,8 I \\
\frac{x-0,8 I}{0,1 I}, 0,8 I<x<0,9 I \\
1,0,9 I \leq x \leq 1,1 I \\
\frac{1,1 I-x}{0,1 I}, 1,1 I<x<1,2 I \\
0, x \geq 1,2 I
\end{array}\right.
\end{aligned}
$$


Математическая модель прогнозирования уровня цен на региональном рынке жилой недвижимости

$$
\mu_{k 3}(x)=\left\{\begin{array}{c}
1, x \geq 1,2 I \\
\frac{x-1,1 I}{0,1 I}, 1,1 I<x<1,2 I \\
0, x \leq 1,1 I
\end{array}\right.
$$

этих термов определены следующие функции принадлежности (формула 10):

где $I$ - средний уровень инфляции в регионе.

$$
\begin{aligned}
& \mu_{k_{1}}(x)=\left\{\begin{array}{c}
1, x \leq 0,8 K \\
\frac{0,9 K-x}{0,1 K}, 0,8 K<x<0.9 K \\
0, x \geq 0,9 K
\end{array}\right. \\
& \mu_{k 2}(x)=\left\{\begin{array}{c}
0, x \leq 0,8 K \\
\frac{x-0,8 K}{0,1 K}, 0,8 K<x<0,9 K \\
1,0,9 K \leq x \leq 1,1 K \\
\frac{1,1 K-x}{0,1 K}, 1,1 K<x<1,2 K \\
0, x \geq 1,2 K
\end{array}\right. \\
& \mu_{k 3}(x)=\left\{\begin{array}{c}
1, x \geq 1,2 K \\
\frac{x-1,1 K}{0,1 K}, 1,1 K<x<1,2 K \\
0, x \leq 1,1 K
\end{array}\right.
\end{aligned}
$$
чения ссудного процента по кредиту. Далее были определены узловые точки, а по этим узловым точкам построены кусочно-линейные и трапециевидные функции принадлежности для всех термов.

Для компонента «уровень ставок по кредитам» определены значения переменной: $k_{1}-$ ниже среднего по стране; $k_{2}$ - соответствует среднему; $k_{3}$ - выше среднего по стране. Для

где $K$ - средний уровень процентной ставки по стране.

Примечание. Разработано авторами по: [7].

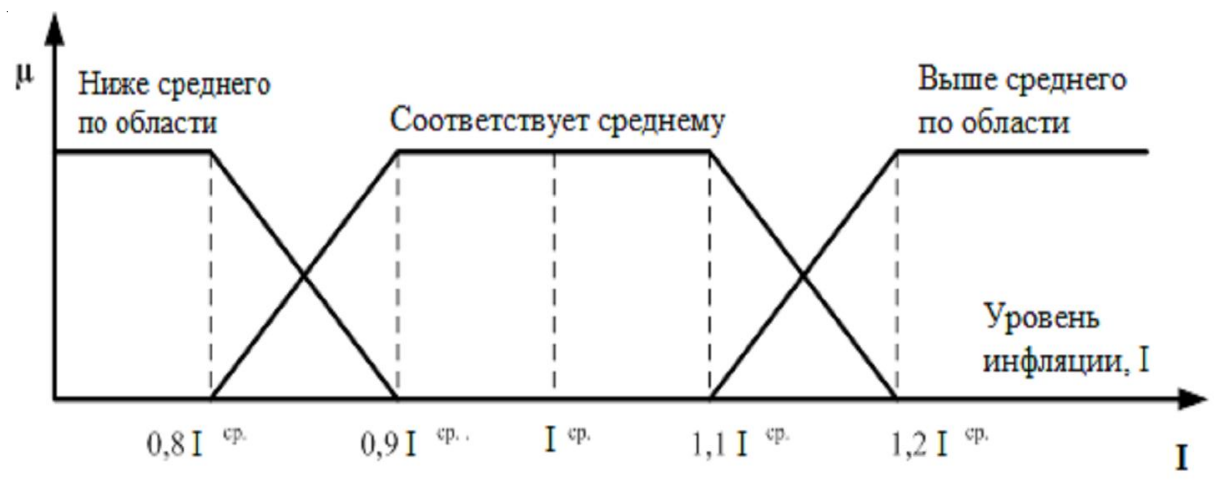

Рис. 10. Нечеткая шкала для показателя «уровень инфляции»

Примечание. Разработано авторами.

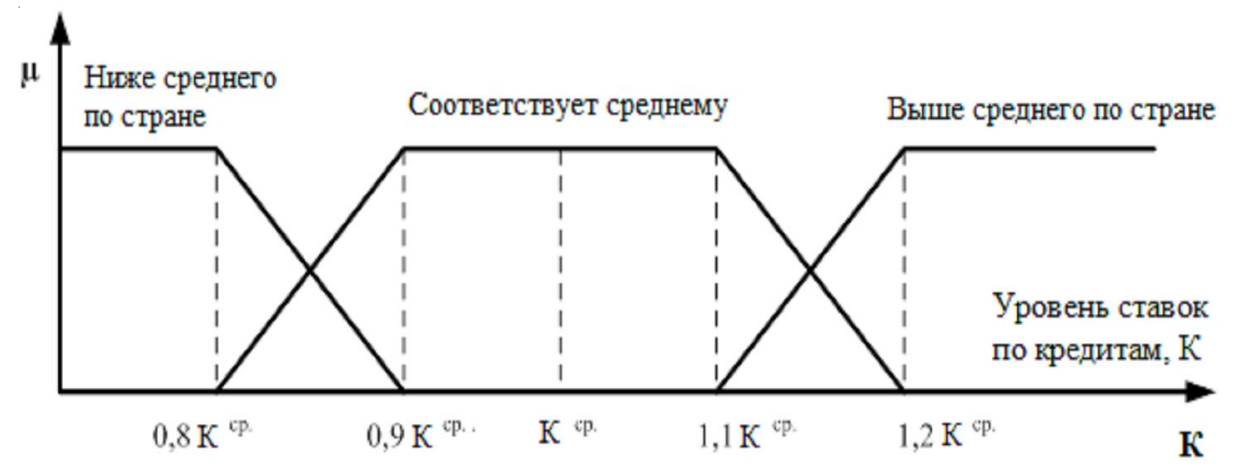

Рис. 11. Нечеткая шкала для показателя «уровень процентной ставки»

Примечание. Разработано авторами. 


\section{Определение итогового значения} стоимости 1 кв. м жилой недвижимости

Для составления прогноза стоимости 1 кв. м жилой недвижимости в регионе необходимо объединить показатели состояния объекта недвижимости (цена за 1 кв. м) и состояние рынка жилой недвижимости в единую систему нечеткого вывода (рис. 12).

Результатами выполнения блоков являются нечеткие множества, полученные путем пересечения нечетких множеств, описывающих входящие критерии (формула 11):

$$
Y=\lambda_{1} \cap \lambda_{2}
$$

где $\lambda_{1}-$ выходная состояния объекта недвижимости (цена за 1 кв. м); $\lambda_{2}-$ выходная переменная состояния рынка жилой недвижимости; $Y$-выходная переменная, определяет уровень цен на рынке жилой недвижимости.

Примечание. Разработано авторами.

Процесс формирования показателя «прогнозная цена» по составляющим нечеткой пе- ременной «состояние объекта недвижимости (цена за 1 кв. м)» и «состояние рынка» с помощью базы правил представлен в таблице 3.

Если результат (база правил) является удовлетворительным, можно переходить к среднесрочному и краткосрочному планированию прогнозной цены на 1 кв. м жилой недвижимости. Если полученный результат неблагоприятен, следует рассмотреть причины, возможно, требуется корректировка процесса определения значения показателя «прогнозная цена» или неудачно были выбраны такие показатели, как «состояние объекта недвижимости (цена за 1 кв. м)» и «состояние рынка».

\section{Заключение}

Представленная в работе модель имеет значительный потенциал для практической реализации: использование не только лингвистической, но и количественной информации (баз данных органов статистики, средств массовой информации, данных ана-

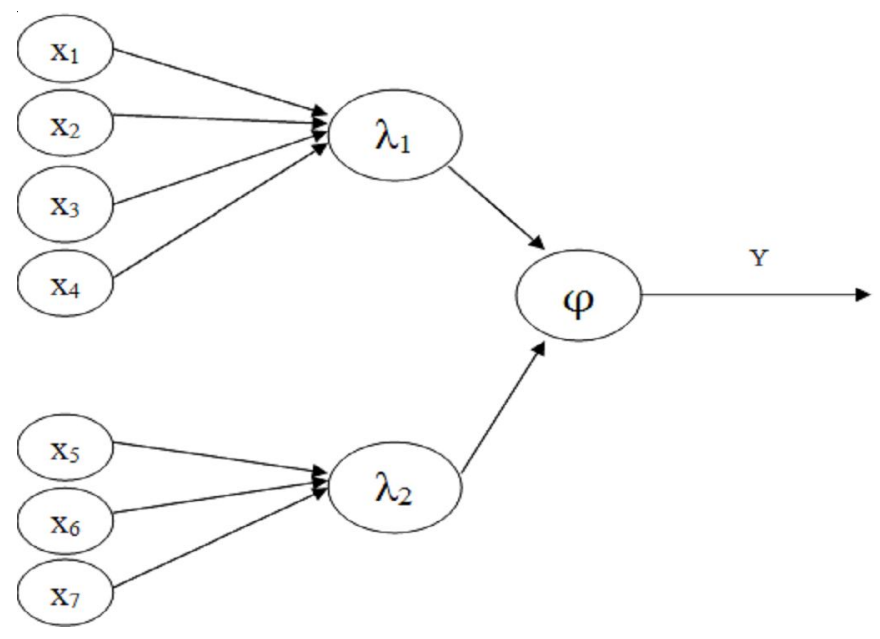

Рис. 12. Система нечеткого вывода

Примечание. Разработано авторами.

Таблица 3

База правил по составляющим нечеткой переменной «прогнозная цена»

\begin{tabular}{|l|c|c|}
\hline \multicolumn{1}{|c|}{ Состояние рынка } & $\begin{array}{c}\text { Величина } \\
\text { изменения цены, \% }\end{array}$ & Методика расчета \\
\hline Значительный спад & -10 & 0,9 Ц 1 кв. м \\
\hline Спад & -5 & 0,95 Ц 1 кв. м \\
\hline Стагнация & 0 & 1 Ц 1 кв. м \\
\hline Слабый рост & +5 & 1,05 Ц 1 кв. м \\
\hline Уверенный рост & $+7,5$ & 1,07 Ц 1 кв. м \\
\hline Сильный рост & +10 & 1,1 Ц 1 кв. м \\
\hline
\end{tabular}

Примечание. Разработано авторами. 
Математическая модель прогнозирования уровня цен на региональном рынке жилой недвижимости

литического и синтетического учета и т. д.), возможность добавления инструментов графической визуализации информации, реализация механизма динамической настройки показателей системы (например, показателя стоимости) в соответствии с желаниями пользователя.

Таким образом, был разработан алгоритм создания математической модели выбора услуг для субъектов рынка услуг в сфере недвижимости. В работе представлена модель системы поддержки принятия решения на основе нечетких множеств и нечеткого вывода. Применение данной системы позволит повысить качество и обоснованность принимаемых решений субъектов малого бизнеса при выборе состава услуг.

\section{ПРИМЕЧАНИЕ}

1 Работа выполнена при частичной финансовой поддержке РФФИ (проект № 17-07-01323).

\section{СПИСОК ЛИТЕРАТУРЫ}

1. Алехина, Е. С. Исследование процессов формирования рынка недвижимости и их влияние на развитие риэлтерских услуг / Е. С. Алехина // Экономика, статистика и информатика. Вестник УМО. -2012. - № 3-2. - С. 183-186.

2. Алехина, Е. С. Формирование и оценка развития рынка риэлтерских услуг и недвижимости в регионе / Е. С. Алехина // Инженерный вестник Дона. - 2012. - № 3 (21). - С. 536-541.

3. Лещинский, Б. С. Согласование субъективной оценки качества жилого объекта недвижимости и рыночной ситуации с использованием теории нечетких множеств / Б. С. Лещинский // Вестник Томского государственного университета. Экономика. - 2013. - № 2 (22). - С. 174-182.

4. Морщинина, Н. И. Становление рынка риэлтерских услуг в сфере жилой недвижимости : автореф. дис. ... канд. экон. наук / Морщинина Наталья Ивановна. - М., 2014. - 25 с.

5. Мухамадиев, А. С. Основные направления развития и регулирования рынка риэлтерских услуг (на материалах Ростовской области) : автореф. дис. ... канд. экон. наук / Мухамадиев Анвар Султанбекович. - Шахты, 2011. - 25 с.

6. Орлов, А. И. Системная нечеткая интервальная математика / А. И. Орлов, Е. В. Луценко. Краснодар : Изд-во КубГАУ, 2014. - 600 с.
7. Пегат, А. Нечеткое моделирование и управление : учеб. пособие / А. Пегат. - М. : Бином. Лаборатория знаний, 2013. - 798 с.

8. Сильнова, С. В. Поддержка принятия решений при управлении предприятием на основе нечетких моделей / С. В. Сильнова, Г. Р. Полюдова, Е. А. Пузырникова // Вестник компьютерных и информационных технологий. -2009 . - № 11. - С. 33-41.

9. Стерник, Г. М. Развитие и совершенствование методов прогнозирования на рынке жилой недвижимости / Г. М. Стерник, С. Г. Стерник, А. В. Свиридов // Урбанистика и рынок недвижимости. - 2014. - № 1. - С. 53-93.

10. Чернов, В. Г. Основы теории нечетких множеств : учеб. пособие / В. Г.Чернов. - Владимир : Изд-во ВлГУ, 2010. - 96 с.

11. Яговцева, М. М. Оценка полезности мультиатрибугивного товара на рынке жилой недвижимости / М. М. Яговцева, Д. Б. Потапов // Маркетинг и маркетинговые исследования. - 2013. - № 3. C. 192-208.

12. Cerami, M. On the relationship between fuzzy description logics and many-valued modal logics / M. Cerami, F. Esteva, À. García-Cerdaña // International Journal of Approximate Reasoning. 2018. - № 93. - P. 372-394.

13. Mathematical model of forecasting the residential real estate market prices level / E. V. Voronina, O. B. Yarosh, N. V. Bereza, N. I. Zakieva // Materials ScienceForum.-2018.-Vol. 931.-P. 1101-1106.-DOI: https://doi.org/10.4028/www.scientific.net/MSF. 931.1101.

14. The principles of analytic decision support system construction on the basis of fuzzy logic / N. V. Bereza, A. N. Bereza, M. V. Lyashov, L. Blanco// The $9^{\text {th }}$ IEEE International Conference on Application of Information and Communication Technologies (AICT2015). - Rostov-on-Don, 2015. - P. 161-166.

15. Yazdanbakhsh, O. A systematic review of complex fuzzy sets and logic / O. Yazdanbakhsh, S. Dick // Fuzzy Sets and Systems. - 2018. - № 338. - P. 1-22.

\section{REFERENCES}

1. Alekhina E.S. Issledovanie protsessov formirovaniya rynka nedvizhimosti i ikh vliyanie na razvitie rielterskikh uslug [The Study of the Processes of the Real Estate Market Formation and Their Impact on the Development of Real Estate Services]. Ekonomika, statistika i informatika. Vestnik UMO, 2012, no. 3-2, pp. 183-186.

2. Alekhina E.S. Formirovanie i otsenka razvitiya rynka rielterskikh uslug i nedvizhimosti $\mathrm{v}$ regione [Formation and Assessment of the Development of the Market of Real Estate Services and Real Estate in 
the Region]. Inzhenernyy vestnik Dona [Engineering Bulletin of the Don], 2012, no. 3 (21), pp. 536-541.

3. Leshchinskiy B.S. Soglasovanie subyektivnoy otsenki kachestva zhilogo obyekta nedvizhimosti i rynochnoy situatsii s ispolzovaniem teorii nechetkikh mnozhestv [Reconciliation of the Subjective Assessment of the Quality of a Residential Property and the Market Situation Using the Theory of Fuzzy Sets]. Vestnik Tomskogo gosudarstvennogo universiteta. Ekonomika [Bulletin of Tomsk State University. Economy], 2013, no. 2 (22), pp. 174-182.

4. Morshchinina N.I. Stanovlenierynka rielterskikh uslug $v$ sfere zhiloy nedvizhimosti: avtoref. dis. ... kand. ekon. nauk [Formation of the Real Estate Services Market. Cand. econ. sci. diss.]. Moscow, 2014. 25 p.

5. Mukhamadiev A.S. Osnovnye napravleniya razvitiya i regulirovaniya rynka rielterskikh uslug (na materialakh Rostovskoy oblasti): avtoref. dis. ... kand. ekon. nauk [The Main Directions of Development and Regulation of the Market of Real Estate Services (on the Materials of the Rostov Region). Cand. econ. sci. diss.]. Shakhty, 2011. 25 p.

6. Orlov A.I., Lutsenko E.V. Sistemnaya nechetkaya intervalnaya matematika [System Fuzzy Interval Math]. Krasnodar, KubGAU Publ., 2014. 600 p.

7. Pegat A. Nechetkoe modelirovanie $i$ upravlenie [Fuzzy Modeling and Control]. Moscow, Binom. Laboratoriya znaniy Publ., 2013. 798 p.

8. Silnova S.V., Polyudova G.R., Puzyrnikova E.A. Podderzhka prinyatiya resheniy pri upravlenii predpriyatiem na osnove nechetkikh modeley [Decision Support in the Management of an Enterprise Based on Fuzzy Models]. Vestnik kompyuternykh $i$ informatsionnykh tekhnologiy [Bulletin of Computer and Information Technologies], 2009, no. 11, pp. 33-41.
9. Sternik G.M., Sternik S.G., SviridovA.V. Razvitie i sovershenstvovanie metodov prognozirovaniya na rynke zhiloy nedvizhimosti [Development and Improvement of Forecasting Methods in the Residential Real Estate Market]. Urbanistika i rynok nedvizhimosti [Urbanism and the Real Estate Market], 2014, no. 1, pp. 53-93.

10. Chernov V.G. Osnovy teorii nechetkikh mnozhestv [Fundamentals of the Theory of Fuzzy Sets]. Vladimir, VlGU Publ., 2010.96p.

11. Yagovtseva M.M., Potapov D.B. Otsenka poleznosti multiatributivnogo tovara na rynke zhiloy nedvizhimosti [Assessment of the Utility of a MultiAttributable Product in the Residential Real Estate Market]. Marketing i marketingovyye issledovaniya [Marketing and Marketing Research], 2013, no. 3, pp. 192-208.

12. Cerami M., Esteva F., García-Cerdaña À. On the Relationship Between Fuzzy Description Logics and Many-Valued Modal Logics. International Journal of Approximate Reasoning, 2018, no. 93, pp. 372-394.

13. Voronina E.V., Yarosh O.B., Bereza N.V.,Zakieva N.I. Mathematical Model of Forecasting the Residential Real Estate Market Prices Level. Materials Science Forum, 2018, vol. 931, pp. 1101-1106. DOI: https:// doi.org/10.4028/www.scientific.net/MSF.931.1101.

14. Bereza N.V., Bereza A.N., Lyashov M.V., Blanco L. The Principles of Analytic Decision Support System Construction on the Basis of Fuzzy Logic. The $9^{\text {th }}$ IEEE International Conference on Application of Information and Communication Technologies (AICT2015). Rostov-on-Don, 2015, pp. 161-166.

15. Yazdanbakhsh O., Dick S. A Systematic Review of Complex Fuzzy Sets and Logic. Fuzzy Sets and Systems, 2018, no. 338, pp. 1-22.

\section{Information about the Authors}

Ekaterina V. Voronina, Candidate for a Degree, Department of Marketing, Trading and Customs Business, Institute of Economics and Management, Crimean Federal University named after V.I. Vernadsky, Sevastopolskaya St., 21/4, 295015 Simferopol, Russian Federation; Postgraduate Student, Department of Intelligent Electrical Networks, Don State Technical University, Gagarina Sq., 1, 344000 Rostov-on-Don, Russian Federation, vev_94katerina@mail.ru, https://orcid.org/0000-0001-6308-0675

Olga B. Yarosh, Doctor of Sciences (Economics), Associate Professor, Professor of Department of Marketing, Trading and Customs Business, Institute of Economics and Management, Crimean Federal University named after V.I. Vernadsky, Sevastopolskaya St., 21/4, 295015 Simferopol, Russian Federation, iarosh.olga@gmail.com, https://orcid.org/0000-0001-9663-2528

Natalya V. Bereza, Candidate of Sciences (Economics), Associate Professor of Department of Information Systems and Radio Engineering, Institute of the Service Sector and Entrepreneurship (Branch) of Don State Technical University, Shevchenko St., 147, 346500 Shakhty, Russian Federation, nvbereza@bk.ru, https://orcid.org/0000-0002-0820-7669

Marina V. Rossinskaya, Doctor of Sciences (Economics), Professor of Department of Economics and Management, Sochi State University, Sovetskaya St., 26a, 354000 Sochi, Russian Federation, rossmv@mail.ru, https://orcid.org/0000-0001-6190-5434 
Математическая модель прогнозирования уровня цен на региональном рынке жилой недвижимости

\section{Информация об авторах}

Екатерина Владимировна Воронина, соискатель кафедры маркетинга, торгового и таможенного дела, Институт экономики и управления (структурное подразделение), Крымский федеральный университет им. В.И. Вернадского, ул. Севастопольская, 21/4, 295015 г. Симферополь, Российская Федерация; аспирант кафедры интеллектуальных электрических сетей, Донской государственный технический университет, пл. Гагарина, 1, 344000 г. Ростов-на-Дону, Российская Федерация, vev_94katerina@mail.ru, https://orcid.org/0000-0001-6308-0675

Ольга Борисовна Ярош, доктор экономических наук, доцент, профессор кафедры маркетинга, торгового и таможенного дела, Институт экономики и управления (структурное подразделение), Крымский федеральный университет им. В.И. Вернадского, ул. Севастопольская, 21/4, 295015 г. Симферополь, Российская Федерация, iarosh.olga@gmail.com, https://orcid.org/0000-0001-9663-2528

Наталья Викторовна Береза, кандидат экономических наук, доцент кафедры информационных систем и радиотехники, Институт сферы обслуживания и предпринимательства (филиал), Донской государственный технический университет в г. Шахты Ростовской области, ул. Шевченко, 147, 346500 г. Шахты, Российская Федерация, nvbereza@bk.ru, https://orcid.org/0000-0002-0820-7669

Марина Васильевна Россинская, доктор экономических наук, профессор кафедры экономики и менеджмента, Сочинский государственный университет, ул. Советская, 26a, 354000 г. Сочи, Российская Федерация, rossmv@mail.ru, https://orcid.org/0000-0001-6190-5434 